\title{
Some Comments on the Ministerial Declaration on the Protection of the North Sea*
}

The Marine Forum welcomes the Ministerial Declaration issued by the participants of the Second International Conference on the Protection of the North Sea, held on 24 and 25 November 1987 , in which several important recommendations of the Forum have largely been met, notably:

1. Under MARPOL 73/78, agreement to continue efforts to bring into force Annexes III and V, and to designate the North Sea a Special Area (albeit only for the purpose of Annex V);

2. To strengthen the Oslo and Paris Conventions;

3. To take effective national steps to reduce inputs including nutrients where pollution effects exist or are likely to occur;

4. To combine a regime of fixed emission standards with meaningful environmental quality standards for the protection of the marine environment, and to review and revise these standards as knowledge improves;

5. To concentrate attention on inputs of contaminants from all sources but especially by the aerial route;

6. To revise and strengthen regulations on the discharge of oil from platforms and use airborne surveillance to aid enforcement; and

7. To promote clean technology.

Governments must now ensure that necessary legislative guidance and resources are available, nationally, to allow implementation of the many recommendations within a reasonable time-scale. However, it is a matter of regret that the Ministers' Declaration is focussed so closely on pollution inputs and fails to address other major issues of concern to the Marine Forum, and, surely, the 'outside world'. In particular the Declaration fails to respond to:

\footnotetext{
* Published on pp. 357-61 of this issue.-Ed.
}

a. The inadequacy of the information that is so far available on the resources of the North Sea and the present impacts on it which are required for sensible management decisions. The comment on the possible joint working group (paragraph 51) does not give confidence that a strong, well-funded international research programme will be forthcoming;

b. The serious threats to wildlife from coastal habitat loss around the shores of the North Sea and from the extraction of marine deposits of sand and gravel;

c. The unresolved conflicts in the exploitation of fish and other wildlife, and the unknown effects of harvesting the smaller industrial fish species at present rates;

d. Calls to end industrial dumping, including material such as Durham colliery waste which, although 'inert' in the sense of the Declaration, is none the less objectionable.

The North Sea Forum had called for a major international effort to establish a comprehensive management regime for the entire North Sea, including coastal habitats, that would be capable of responding to unpredicted changes in relevant environmental features, and the Marine Forum was established in July 1987 to carry on its work. The initiative of the Wadden Sea states provides a lead in this respect, but there is no sign of a wider, comprehensive approach. This should be the task of the next such Conference, to be held in the Netherlands in 1990.

EARL OF CRANBROOK, Chairman
The Marine Forum
clo CoEnCo
80 York Way
London NI $9 A G$
England, UK.

\section{The Alps in Danger}

An international group of mountain experts, meeting in France, claims that the Alps have now become 'the most threatened mountain system in the world.' This conclusion was reached at a recent conference held in Chambéry, France, organized by IUCN, the world's foremost scientific conservation organization.

According to the Conference's Chairman, Frédéric Briand, the experts drew particular attention to the death of forests, the decline of agricultural and mountain communities, the pressures of excessive tourism, unacceptably high levels of road traffic, and air and water pollution-all affecting, to various degrees, the flora, fauna, and natural habitats, of Alpine regions. Dr Briand said that it is the cumulative effect of these various stresses that worries the experts and now places the Alps in the most devastating situation indicated in the above quotation.

The group at the above-mentioned conference, representing Alpine countries from France to Yugoslavia as well as international agencies such as UNESCO and the International Commission for the Protection of Alpine Regions (CIPRA), have called for the establishment of an International Centre for the Alpine Environment. The Conseil Général de Savoie, which hosted the meeting, welcomed this initiative and proposed the necessary support to establish such a centre in that region of France.

Meanwhile the international experts say immediate action is needed to relieve and ultimately improve the situation. Their recommendations call for: more effective legislation, including the elaboration of an Alpine Convention; improved application of the legislation and communication systems; greater coordination of research and action-oriented programmes than currently obtains; and more effective international cooperation and better communication of scientific knowledge aimed at decisionmakers and users of the Alps.

According to Briand, one of the obstacles to expeditious dealing with the problems in the past has been the linguistic barrier among Alpine countries, whereas 'The proposed new centre, by virtue of its international character, would help to break down the existing barriers'. For further information please write to the undersigned:
DAVID PITT
IUCN Mountain Programme
World Conservation Centre
Avenue du Mont-Blano
1196 Gland, Switzerland. 